\title{
Effects of Hydrogen Introduction on Electrical and Optical Properties of Cd-doped Ge Oxide and Zn Oxide Thin Films
}

\author{
Makoto Arita, Hirofumi Konishi*1, Kouichi Matsuda ${ }^{* 2}$, \\ Masataka Masuda and Yasunori Hayashi \\ Department of Materials Science and Engineering, Faculty of Engineering, Fukuoka 812-8581, Japan
}

Cadmium-doped Ge oxide and Zn oxide thin films were deposited by RF magnetron sputtering. The electrical and optical properties of these films were investigated. All deposited films except for highly Cd-doped Ge oxide were transparent to visible light. Hydrogen introduction reduced the resistivity of the films, although the optical transmittance for visible light did not change significantly. The enhancement of conductivity could be attributed to the increase in carrier density by the hydrogen introduction.

(Received November 20, 2001; Accepted January 21, 2002)

Keywords: cadmium oxide, germanium oxide, zinc oxide, thin film, visible light transparency, electrical conductivity, hydrogen introduction

\section{Introduction}

There are some oxides which possess both high conductivity and transparency, though most oxides are optically transparent but are electrically insulating. They are called transparent conductive oxides (TCOs). Recently TCO thin films have been used for the transparent electrodes in liquid crystal displays or solar cell panels. Indium-tin oxide (ITO) and $\mathrm{SnO}_{2}$ are used mainly in these applications. It is, however, still required to have higher conductivity and more stability in various environments. On the other hand, induction of electric conductance of other transparent oxides by a new technique might widen the choice of TCOs for various applications.

One of the crucial parameters that governs the conductivity is carrier density of oxides. The carrier density would be controlled by impurity doping. For example, ITO is a material of tin-doped indium oxide. It has been reported that the electrical conductivities of $\mathrm{SnO}_{2}$ and $\mathrm{ZnO}$ were improved by the doping of $\mathrm{F}, \mathrm{Sb}^{1-4)}$ and $\mathrm{Al},{ }^{5-7)}$ respectively. Generally, to make the conductivity of oxides better, hydrogen introduction will be a good candidate. It is considered that the introduced hydrogen behaves as a donor or an acceptor in the materials and makes the density of electrical charge carrier high. The hydrogen introduced into the oxides, however, sometimes gives coloration to the oxides. So the change of the optical properties by hydrogen introduction must be considered when TCO materials are studied.

In this work, optical and electrical properties of two types of oxides deposited by RF sputtering were investigated and the effect of hydrogen introduction on them was examined. We used hydrogen gas exposure as well as hydrogen ion implantation to introduce hydrogen into the oxides. The oxide films examined in this study were $\mathrm{Cd}$-doped $\mathrm{Ge}$ oxides $(\mathrm{Ge}-$ $\mathrm{Cd}$ oxide) and $\mathrm{Zn}$ oxides. $\mathrm{Ge}-\mathrm{Cd}$ oxides have been studied by some researchers. ${ }^{8,9)}$ There are some reports on TCO of Zn oxide films also. Aranovich et al. ${ }^{10)}$ and Bahadur et al. ${ }^{11)}$

\footnotetext{
${ }^{* 1}$ Graduate Student, Kyushu University.

${ }^{* 2}$ Graduate Student, Kyushu University. Present address: Mazda Motor Corporation, Hiroshima 730-91, Japan.
}

investigated the optical and electrical properties of $\mathrm{ZnO}$ films prepared by spray pyrolysis and with annealing in hydrogen atmosphere. However, no study on hydrogen ion implantation into $\mathrm{Zn}$ oxide films has been performed yet.

\section{Experimental Procedure}

All oxide films were deposited on fused silica glass with an RF sputtering apparatus ULVAC BC2227. The deposited area was $12 \times 12 \mathrm{~mm}^{2}$. The base pressure of the chamber was $1.3 \times$ $10^{-3} \mathrm{~Pa}$, and the distance between the substrate and the target was $60 \mathrm{~mm}$. For deposition of $\mathrm{Ge}-\mathrm{Cd}$ oxide films, we used a commercial sintered $\mathrm{CdO}$ disk $(99.99 \%)$ as the sputtering target with Ge (99.999\%) tips on it occupying $20 \%$ of the $\mathrm{CdO}$ surface area. The $\mathrm{Ge} / \mathrm{Cd}$ ratio of the deposited films was varied by the configuration of the Ge tips on the $\mathrm{CdO}$ disk surface. The sputtering gas was the mixture of $\mathrm{O}_{2}$ and Ar. The fraction of $\mathrm{O}_{2}$ ranged from 20 to $80 \%$, and the total pressure was 2.7-11 $\mathrm{Pa}$. The RF power of $50 \mathrm{~W}$ was applied. For deposition of $\mathrm{Zn}$ oxide film, a commercial sintered $\mathrm{ZnO}$ disk $(99.99 \%)$ was used as a target. The sputtering gas was $\mathrm{Ar}$ and the total pressure was $6.7 \times 10^{-1}-2.7 \mathrm{~Pa}$. The RF power of $100 \mathrm{~W}$ was applied.

To characterize the structure of deposited films XRD measurements were performed with $\mathrm{Cu} \mathrm{K} \alpha$ radiation. The transmittance spectra of the oxide films were measured in the range from 200 to $1100 \mathrm{~nm}$ using Shimadzu UV160A UVvisible spectrophotometer. The resistivity of the films was estimated by Van der Pauw method with four probes at a constant current of $5 \mathrm{nA}-0.1 \mathrm{~mA}$. For the $\mathrm{Zn}$ oxide films the Hall measurement was performed and the carrier density was estimated.

$\mathrm{H}_{2}^{+}$ions were implanted into the oxides using an ion gun with the acceleration voltage of $4.8 \mathrm{kV}$ for $\mathrm{Ge}-\mathrm{Cd}$ oxides and $1 \mathrm{kV}$ for $\mathrm{Zn}$ oxides, respectively. The ion current was about $2 \mu \mathrm{A}$ and the implanted hydrogen dose was $0.4-1.2 \times$ $10^{17}$ ions $/ \mathrm{cm}^{2}$. We have performed the hydrogen exposure experiment for $\mathrm{Zn}$ oxide films. A chamber contained the sample was first evacuated by a turbo molecular pump and a rotary 
pump, then filled with hydrogen gas of $1 \times 10^{5} \mathrm{~Pa}$ and retained 7 days. In order to enhance the hydrogen introduction on the hydrogen gas exposure test, a very thin Pd layer was deposited on the $\mathrm{Zn}$ oxide surface by RF sputtering. For Pd layer deposition, a Pd disk was used as a target and the sputtering gas was Ar. The RF power of $10 \mathrm{~W}$ was applied for $2 \mathrm{sec}$.

\section{Results and Discussion}

\subsection{Ge-Cd oxide films}

With the fraction of $50 \% \mathrm{O}_{2}$, total pressure of $2.7 \mathrm{~Pa}$, and the sputtering time of $1.5 \mathrm{~h}$, a $\mathrm{Ge}-\mathrm{Cd}$ oxide film was deposited. The ratio of $\mathrm{Ge} / \mathrm{Cd}$ was about 0.7 and the thickness was about $750 \mathrm{~nm}$ (Cd-rich film). While with another configuration of $\mathrm{Ge}$ tips on the $\mathrm{CdO}$ target, total pressure of $11 \mathrm{~Pa}$, and the $1.5 \mathrm{~h}$ deposition, an oxide film having the $\mathrm{Ge} / \mathrm{Cd}$ ratio of 1.8 was formed (Ge-rich film). The thickness of this film was about $200 \mathrm{~nm}$. Figure 1 shows the XRD profiles for these two films. For the Cd-rich film diffraction peaks were observed between $30^{\circ}$ and $40^{\circ}$ in $2 \theta$ indicating a crystalline structure. While the Ge-rich film showed no diffraction peak but a very broad one around $30^{\circ}$ suggests amorphous structure, where the broad peak around $20^{\circ}$ is due to the diffraction from the silica substrate. The transmittance spectrum for the Ge-rich film is shown in Fig. 2. The spectrum for the Gerich film displays the fundamental absorption edge at about $300 \mathrm{~nm}$ and the transparency for the visible light was over $90 \%$. The band gap energy of $5.3 \times 10^{-19} \mathrm{~J}(3.3 \mathrm{eV})$ was estimated from Tauc plot eq. (1) of the transmittance spectrum.

$$
\alpha \propto\left(h v-E_{g}\right)^{2} / h v
$$

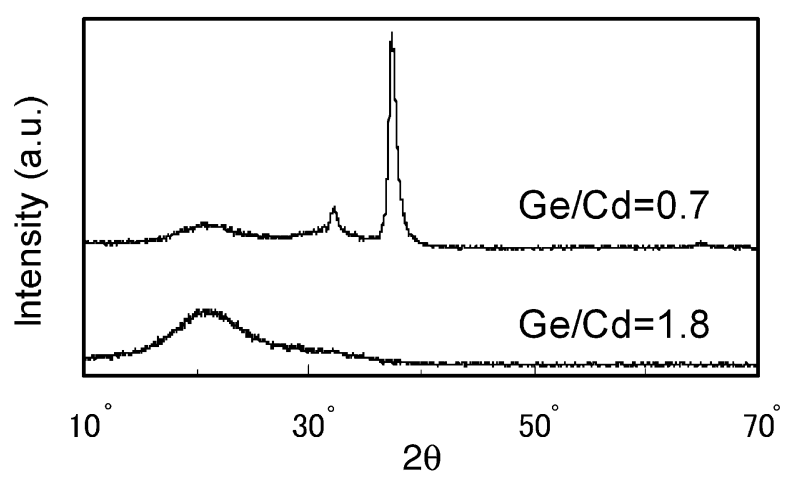

Fig. 1 XRD profiles for Cd-Ge oxide films.

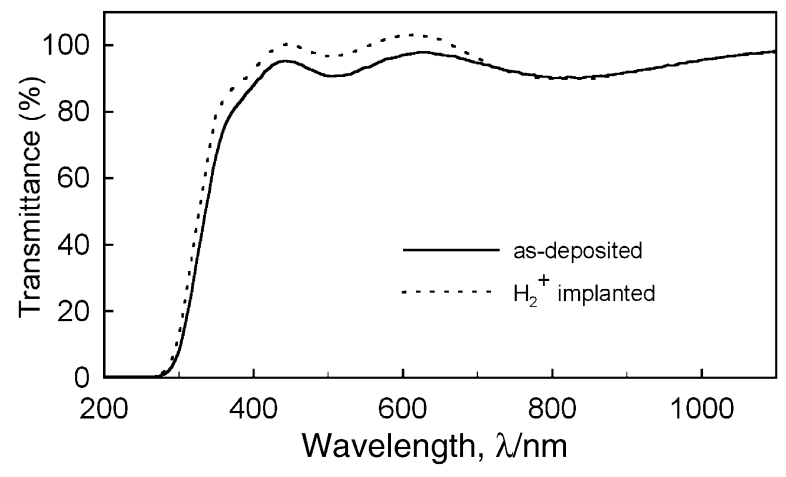

Fig. 2 Transmittance spectra for the Ge-rich Ge-Cd oxide film.
Here, $\alpha$ is the absorption coefficient calculated from the transmittance, $h v$ the photon energy, and $E_{g}$ the band gap energy of the oxide. Figure 3 shows the transmittance spectrum of the Cd-rich film. The fundamental absorption edge lies between 400 and $500 \mathrm{~nm}$ corresponding to the band gap energy of $3.5 \times 10^{-19} \mathrm{~J}(2.2 \mathrm{eV})$. This film showed yellow color. The transmittance spectra for the oxide films showed oscillations in the high transmittance region, which were attributed to the interference of light in the oxide layer. Table 1 summarizes the electrical resistivity of these two films. The Cd-rich film showed $1 \times 10^{-1} \Omega \mathrm{m}$, while the Ge-rich film showed considerably high resistivity $\left(>10^{4} \Omega \mathrm{m}\right.$ ) so that the exact value could not be evaluated by the apparatus.

Using an ion gun, $\mathrm{H}_{2}^{+}$ions were implanted into the films. The ion energy was $4.8 \mathrm{keV}$ and the implanted dose was $4 \times 10^{16}$ ions $/ \mathrm{cm}^{2}$. After the implantation, the Cd-rich film showed a small decrease in transmittance below the absorption edge but there was no significant change in the fundamental absorption edge and the band gap energy. In contrast with the optical properties, the electric conductivities of both the films were considerably improved by the hydrogen ion implantation. After the ion implantation the resistivities of both the films were reduced over 2 orders of magnitude as shown in Table 1. Kikuchi et al. ${ }^{9)}$ studied the effect of hydrogen ion implantation on the electrical properties of $\mathrm{Cd}-\mathrm{Ge}$ amorphous films and reported that the films of the $\mathrm{Ge} / \mathrm{Cd}$ ratio of which was smaller than 0.25 showed over 10 orders of magnitude of decrease in resistivity by $\mathrm{H}^{+}$implantation with the acceleration voltage of $80-140 \mathrm{kV}$. They suggested that improvement of conductivity of the oxides is due to the increase in carrier density. The mechanism of the decrease in resistivity in our study would be also attributed to the increase in carrier density. Kikuchi et al. also reported that there was no effect on resistivity of the oxides with the Ge content over $56 \%$. In our study, the effect of hydrogen implantation on the Ge-rich oxide film was observed. So the effects of hydrogen introduction would depend on various implantation conditions and structures of oxide films.

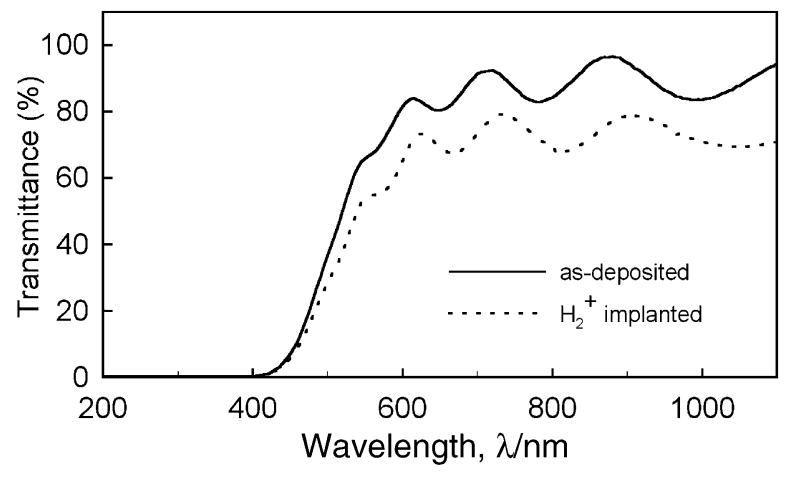

Fig. 3 Transmittance spectra for the Cd-rich Ge-Cd oxide film.

Table 1 Resistivities of Cd-Ge oxide films.

\begin{tabular}{lcc}
\hline & $\mathrm{Ge} / \mathrm{Cd}=0.7$ & $\mathrm{Ge} / \mathrm{Cd}=1.8$ \\
\hline as-deposited & $1 \times 10^{-1} \Omega \mathrm{m}$ & $>10^{4} \Omega \mathrm{m}$ \\
$4 \times 10^{16} \mathrm{H}_{2}^{+}$implanted & $6 \times 10^{-4} \Omega \mathrm{m}$ & $3 \times 10^{2} \Omega \mathrm{m}$
\end{tabular}




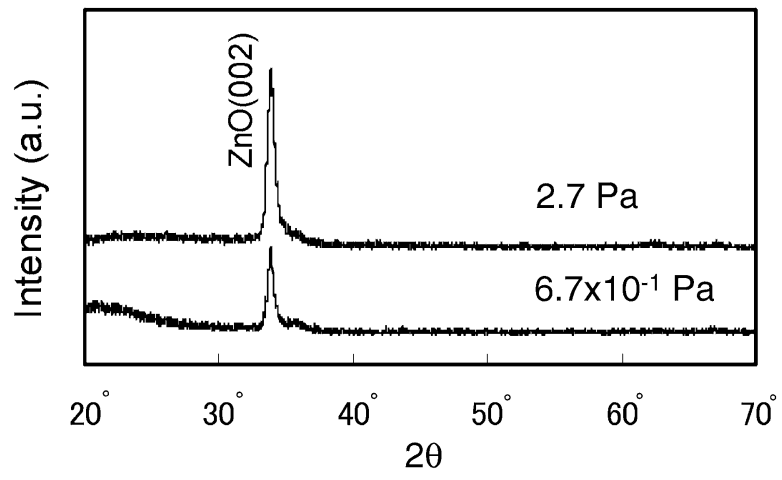

Fig. 4 XRD profiles for $\mathrm{Zn}$ oxide films.

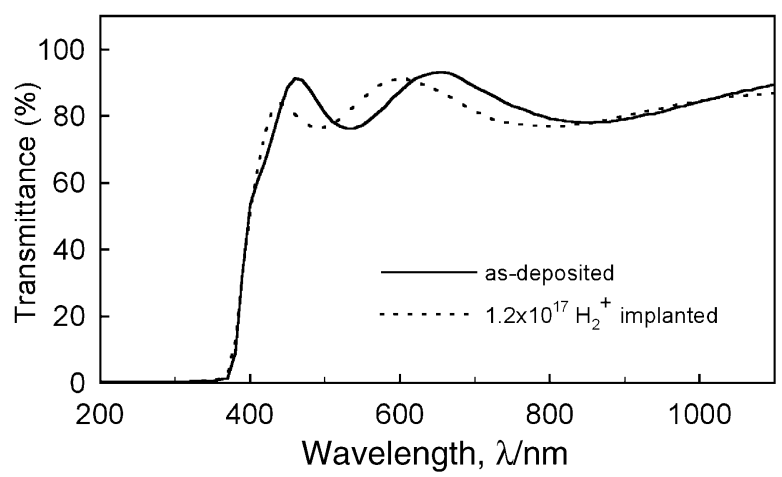

Fig. 5 Transmittance spectra for the $\mathrm{Zn}$ oxide film deposited at $6.7 \times 10^{-1} \mathrm{~Pa}$ of Ar pressure.

Table 2 Resistivities and carrier densities of the $\mathrm{Zn}$ oxide films deposited at $6.7 \times 10^{-1} \mathrm{~Pa}$ of Ar pressure.

\begin{tabular}{lcc}
\hline & Resistivity & Carrier density \\
\hline as-deposited & $9.9 \times 10^{1} \Omega \mathrm{m}$ & $3.6 \times 10^{18} \mathrm{~m}^{-3}$ \\
$1.2 \times 10^{17} \mathrm{H}_{2}^{+}$implanted & $1.1 \times 10^{-4} \Omega \mathrm{m}$ & $3.6 \times 10^{23} \mathrm{~m}^{-3}$ \\
\hline
\end{tabular}

\subsection{Zn oxide films}

The XRD profiles of $\mathrm{Zn}$ oxide films deposited at $2.7 \mathrm{~Pa}$ and $6.7 \times 10^{-1} \mathrm{~Pa}$ of Ar pressure are shown in Fig. 4. The thicknesses of the two films were about $150 \mathrm{~nm}$. Diffraction peaks of wulzite $\mathrm{ZnO}(002)$ appear at about $33^{\circ}$ in $2 \theta$. Figure 5 shows the transmittance spectra for the $\mathrm{Zn}$ oxide film deposited at $6.7 \times 10^{-1} \mathrm{~Pa}$ of Ar pressure after and before the hydrogen implantation. The fundamental absorption edge lies around $400 \mathrm{~nm}$. The band gap energy values were estimated for direct optical transition by the eq. (2), and were $5.1 \times 10^{-19} \mathrm{~J}(3.2 \mathrm{eV})$ for both films.

$$
\alpha \propto\left(h v-E_{g}\right)^{0.5} / h v
$$

Hydrogen ions were implanted into the film with the acceleration voltage of $1 \mathrm{kV}$ and the implanted dose of $1.2 \times$ $10^{17}$ ions $/ \mathrm{cm}^{2}$. After the implantation the absorption edge and the band gap energy did not change. Table 2 shows the resistivities and carrier densities of the film after and before the hydrogen ion implantation. From the Hall measurement it is confirmed that the conduction type of the $\mathrm{Zn}$ oxide films was n-type. The resistivity of the as-deposited film was $9.9 \times 10^{1} \Omega \mathrm{m}$. After the implantation the value reduced to $1.1 \times 10^{-4} \Omega \mathrm{m}$. Corresponding to the resistivity the carrier

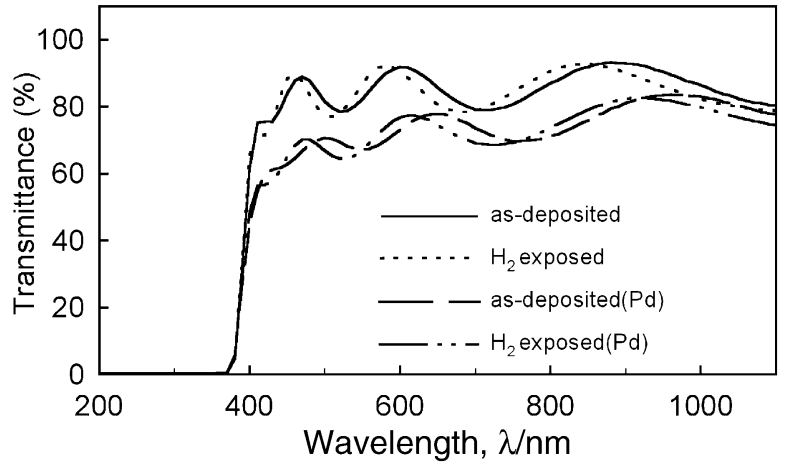

Fig. 6 Transmittance spectra for the $\mathrm{Zn}$ oxide film deposited at $2.7 \mathrm{~Pa}$ of Ar pressure.

Table 3 Resistivities and carrier densities of the $\mathrm{Zn}$ oxide film deposited at 2.7 $\mathrm{Pa}$ of Ar pressure.

\begin{tabular}{lcc}
\hline & Resistivity & Carrier density \\
\hline as-deposited & $1.9 \times 10^{2} \Omega \mathrm{m}$ & $1.2 \times 10^{18} \mathrm{~m}^{-3}$ \\
7 day $\mathrm{H}_{2}$ exposure & $2.5 \times 10^{2} \Omega \mathrm{m}$ & $9.1 \times 10^{17} \mathrm{~m}^{-3}$ \\
\hline
\end{tabular}

Table 4 Resistivities and carrier densities of the $\mathrm{Zn}$ oxide film deposited at 2.7 $\mathrm{Pa}$ of Ar pressure with Pd coating on the surface.

\begin{tabular}{lcc}
\hline & Resistivity & Carrier density \\
\hline as-deposited & $6.6 \times 10^{1} \Omega \mathrm{m}$ & $5.1 \times 10^{17} \mathrm{~m}^{-3}$ \\
7 day $\mathrm{H}_{2}$ exposure & $2.5 \times 10^{-1} \Omega \mathrm{m}$ & $1.9 \times 10^{20} \mathrm{~m}^{-3}$ \\
\hline
\end{tabular}

density increased several orders of magnitude. This indicates the improvement of the conductivity of the $\mathrm{Zn}$ oxide film is due to the increase in carrier density induced by hydrogen ion implantation.

Figure 6 shows the transmittance spectra for the films deposited at $2.7 \mathrm{~Pa}$ of Ar pressure. The spectrum for the asdeposited film had the absorption edge at $400 \mathrm{~nm}$ and showed the transparency of around $80 \%$ in the visible region. By the eq. (2), the calculated $E_{g}$ value was $5.1 \times 10^{-19} \mathrm{~J}(3.2 \mathrm{eV})$. For this film the hydrogen gas exposure test was performed. After the exposure for 7 days there was no significant change observed. The resisitvity of this $\mathrm{Zn}$ oxide film is summarized in Table 3. The resistivity of the as-deposited film was about $2 \times 10^{2} \Omega \mathrm{m}$ then the value remained constant or slightly increased with the exposure to hydrogen gas. The carrier density also showed no significant variation after and before the exposure.

To enhance hydrogen introduction, a very thin Pd layer was deposited on the surface of some of the samples by RF sputtering. The spectrum for the Pd-coated $\mathrm{Zn}$ oxide sample is also shown in Fig. 6 and the resisitvity of the film are listed in Table 4. With the Pd coating the absorption edge of the sample did not change, but the transmittance decreased from 80 to $60 \%$ in the visible range of wavelength. The hydrogen gas exposure test did not affect on the transmittance spectrum of the Pd-coated sample. While the Pd coated sample showed a decrease in the resistivity and an increase in the carrier density of two orders of magnitude. Similar to the case of the hydrogen ion implantation the improvement of the conductivity is due to the increase in the carrier density induced by the exposure to hydrogen gas. It is confirmed that the surface 
Pd layer activates hydrogen incorporation. Palladium has a high permeability and solubility for hydrogen therefore hydrogen is easily introduced from gas phase into oxide films. It is considered that the introduced hydrogen by gas exposure as well as ion implantation behaves as a donor and makes the density of charge carrier high.

\section{Summary}

Cadmium-doped Ge oxide and $\mathrm{Zn}$ oxide thin films were deposited by RF magnetron sputtering. The electrical and optical properties of these films were investigated and the effect of hydrogen introduction on them was examined. All deposited films except for highly Cd-doped Ge oxide were transparent to visible light. Hydrogen ion implantation reduced the resistivity of the films. Hydrogen gas exposure also enhanced the conductivity of the $\mathrm{Zn}$ oxide film with the help of a $\mathrm{Pd}$ coating on the surface. The optical transmittance for visible light wasn't changed significantly by both the hydrogen ion implantation and the gas exposure. The enhancement of conductivity could be attributed to the increase in carrier density by the hydrogen introduction.

\section{Acknowledgements}

This work has been supported in part by a Grant-in-Aid for Scientific Research on Priority Areas A of 'New Protium
Function' from the Ministry of Education, Culture, Sports, Science and Technology.

\section{REFERENCES}

1) J. Kane, H. P. Schweizer and W. Kern: J. Electrochem. Soc. 123 (1976) 270-277.

2) T. Ishida, O. Tabata, J. I. Park, S. H. Shin, H. Magara, S. Tamura, S. Mochizuki and T. Mihara: Thin Solid Films 149 (1996) 228-231.

3) E. Shanthi, V. Dutta, A. Banerjee and L. Chopra: J. Appl. Phys. 51 (1980) 6243-6251.

4) E. Shanthi, A. Banerjee, V. Dutta and L. Chopra: J. Appl. Phys. 53 (1980) 1615-1621.

5) K. H. Kim, K. C. Park and D. Y. Ma: J. Appl. Phys. 81 (1997) 77647772.

6) K. C. Park, D. Y. Ma and K. H. Kim: Thin Solid Films 305 (1997) 201-209.

7) M. L. Addonizio, A. Antonaia, G. Cantele and C. Privato: Thin Solid Films 349 (1999) 93-99.

8) E. R. Whipple and S. N. Subbarao: J. Sol. State Chem. 34 (1980) 231239.

9) N. Kikuchi, H. Hosono, H. Kawazoe, K. Oyoshi and S. Hishita: J. Am. Ceram. Soc. 80 (1997) 22-26.

10) J. Aranovich, A. Ortiz and R. H. Bube: J. Vac. Sci. \& Technol. 16 (1979) 994-1003.

11) L. Bahadur, M. Hamdani, J. F. Koenig and P. Chartier: Solar Energy Materials 14 (1986) 107-120. 